\title{
Attitude Change Process in Group-Level Collaborative Activities: Descriptions of Interaction via a Conversation Analysis Approach
}

\author{
Yuto Kimura
}

Institute of Education and Student Affairs, Niigata University, Japan

\begin{abstract}
Keywords:

Attitude change, Collaborative activities, Conversation analysis approach, Implicit coordination, Order formation

Received

15 April 2021

Received in revised form

27 April 2021

Accepted

28 April 2021

*Correspondence:

yutokmr@gmail.com

In group-level collaboration at work, there is a mutual dynamic in which members are influenced by the attitudes of others while also influencing the attitudes of others. However, it is difficult to depict the phenomenon of group change itself via questionnaires and interviews. Therefore, in this study, we conducted a protocol analysis for voice data from a meeting to examine the attitude change within a group in detail. Protocol data were acquired from educational program development through industry-academia collaboration in Japan, and we analyzed conversation data with the following two aims. The first aim was to quantitatively confirm the basic tendency of the speaker type and the descriptive pattern in the work scene classified with a classified descriptive form code. The second aim was to describe the attitude changes of group members via interpretive analysis of group-level utterance cases using descriptive codes. The analysis indicates that an implicit cooperative relationship may have occurred in terms of the speakers' role and the pattern of speech. Specifically, the results suggest that two members dared to express conflicting attitudes and changed the overall opinion while respecting the opinions of members of other organizations. These are among the results of the quantitative analysis of the utterance structure using descriptive form codes as the basic data for conversation analysis. In practice, these findings could be applied to deliberately control the attitudes of members within an organization.
\end{abstract}

CCIKD Publishing

Team-based activities are an important activity in linking individual activities to the achievement of organizational goals (Edmondson, 2002). In group-level collaborative activities, group members share information such as individual thoughts and perspectives and change attitudes and behaviors through collective dialogue within the team (West, 1996). Analysis of such group-level collaborative activities has been active since the 1990s and has been studied via experiments, case 
studies, and questionnaire surveys. In this way, expectations for teams in academia are rising, and there seems to be a belief that collective collaborative activities will emerge and influence the ideas and perspectives of individual members. However, in classical social psychology experiments, it is often confirmed that such group-level decision-making does not always work properly (Asch, 1951; Janis, 1972; Latané, Williams, \& Harkins, 1979). Researchers have clarified that the attitude of group members is influenced by others in the group (Baron \& Roper, 1976).

In fact, members with different backgrounds in their work build concepts through discussions, and their opinions repeatedly spread and converge in conflicts. Therefore, when carrying out projects and team activities within an organization in practice, we are conscious of how attitudes toward customers, tasks, goals, etc., will change or can be changed. If not controlled, such attitudes may hinder group-level cooperative activities. Clarifying the mechanism of attitude change within a group may assist in intentionally adjusting and integrating the values within the group, so it is significant to examine this from the practical perspective of organizational management.

However, when approaching such a problem, the choice of research method can be challenging. For example, interviews and questionnaire surveys, which are the mainstream in organizational behavior research, basically provide retrospective answers, which may be distorted due to cognitive bias. In addition, in experimental research methods used mainly in psychology, adaptability to the real world becomes an issue. Hence, the actual situation in practical settings at work sites has not been fully clarified in terms of changes in attitudes due to interactions between group members as described above.

Therefore, in this study, we aim to examine the attitude change of group members by analyzing their conversations in the interaction process of an actual workgroup using protocol data. This approach, which is intended to clarify the process of transformation in how group members influence each other to form mutual attitudes, is novel because it uses descriptions of actual cooperative activities at the group level. Thus, in the following, we will first review previous studies on the relationship between individual attitude change and groups. Then, through protocol analysis, we discuss the applicability of describing the interaction process based on conversation data from group members.

\section{Changes in Individual Attitudes within a Group}

Attitude refers to psychological tendencies based on subject preferences and evaluative judgment (Eagly \& Chaiken, 1993, 1998). A person's attitude has two functions. One is an informational function that weighs the advantages and disadvantages of the target and makes selections and decisions based on them. The other is the interpersonal function that forms the basis of identity by expressing one's beliefs and values to others. In this way, individuals absorb information from the outside to create their preferences, make decisions, and simultaneously build relationships with others by expressing their values. Especially in group-level collaborative activities, there is a mutual dynamic in which members are influenced by the attitudes of others while also influencing the attitudes of others.

How is the process by which a person forms an attitude about an object explained? Classically, individual attitude change is interpreted as a behavioral acquisition process that applies learning theory (Lott \& Lott, 1968). In society, people are strengthened in their attitudes by receiving rewards for their beliefs and actions to be approved by others, and they will not be punished by others. In other words, people are socialized and acquire attitudes in the process of developing 
group norms. This also applies within organizations. A group of studies on adaptation processes in the organizational socialization of employees and attitude change via education and training in the workplace would be typical cases (Basadur, Graen, \& Scandura, 1986; Van Maanen \& Schein, 1979).

As a constructive critique of these theories, a group of studies on cognitive consistency theory emerged. This theory considers that the human cognitive system has a function to spontaneously restore equilibrium when an imbalanced state is created, in addition to a simple mechanism such as conditioning in learning. A typical theory is cognitive dissonance theory (Festinger, 1957). People generally feel uncomfortable with conflicting opinions, attitudes, knowledge, and values within themselves and tend to change their attitudes with the motivation to reduce that discomfort. These studies show that attitudes are a precursor to behavior and can add to the meaning of behavior. A well-known method for practically applying such a mechanism is a sneak-in technique (foot-inthe-door technique), a kind of stepwise request technique. Foot-in-the-door is a technique that increases the acceptance rate of larger requests by first obtaining acceptance of smaller requests (Burger, 1999). In particular, people's attitude change is facilitated by the self-perception that the request is not forced by others but is self-determined (Freedman, \& Fraser, 1966).

By applying studies on attitude formation, research on persuasion and attitude change is conducted to examine methods of changing the attitudes of others. Receiving a persuasive message does not mean that people will change their attitude. Petty and Cacippo (1986) proposed the Elaboration Likelihood Model (ELM) to explain these cases. According to those authors, in the absence of individual motivation or ability for persuasive communication, superficial and shallow information processing is carried out, and one's old attitude is maintained. Peripheral information, such as the opinions of experts and the number of pros and cons, can cause attitude changes that are often temporary and superficial. On the other hand, when an individual's motivation and ability are sufficient, fundamental, deep information processing occurs, and favorable or unfavorable attitudes are transformed or strengthened. Thus, their model shows that an individual's interest in a persuasive message determines whether peripheral cues process it or whether the content of the message itself is elaborately processed. This model is known as the basic model of attitude change and is also called the dual-process model of persuasion. A similar dual-process model includes the Heuristic Systematic Model (HSM), which focuses on saving and utilizing cognitive resources (Chaiken, Liberman, \& Eagly, 1989).

These theories about attitude change can also be applied to organizational management. For example, in situations of organizational change, it may be effective to apply knowledge of social psychology, such as minority influence, in addition to using cognitive dissonance theory as mentioned above. In the theory of minority influence, the minority shows a flexible attitude toward the majority for many events while maintaining a consistent attitude and behavior for one event. Research has shown that the minority can change the attitude of the majority (Nemeth, Swedlund, \& Kanki, 1974; Paicheler, 1977). Thus, the impact of minorities can be a driving force for group change and can be one of the important perspectives when considering the relationship between cooperative activities and attitude change within a group. However, it has not yet been demonstrated how cognitive dissonance theory and minority influence occur in the actual field interaction process within an organization. Therefore, future research is warranted. 


\section{Applicability of Protocol Analysis}

In exploring such issues of attitude change among group members, methods such as examinations in laboratory situations, attitude surveys using questionnaires, and interviews have been the main methods (Basadur et al., 1986). In fact, only a limited number of studies have explored the work interaction scene (e.g., Suchman, 1997; Murphy, 2005). Perhaps one of the reasons is that real-life work meetings often contain confidential information, making them difficult to use as sites for research. However, as mentioned in the previous section, it is difficult to depict group changes via questionnaires and interviews. In addition, the applicability of experimental methods in practical situations is an issue. Based on the above, in this study, we conduct a protocol analysis for voice data from a meeting to examine the attitude change within a group in detail.

Protocol analysis is a method of cognitive psychology that analyzes the subject's internal cognitive process through detailed analysis of protocol data from the spoken language of the observer (Ericsson \& Crutcher, 1991; Ericsson \& Simon, 1993). There are roughly two types: introspection analysis and conversation analysis. Introspection analysis arises from a critical examination of Wundt's introspection method and infers the cognitive processing and transformation process of the subject in problem-solving situations (Anzai \& Simon, 1979; Newell $\&$ Simon, 1972). Conversation analysis is also applied to the field of psychology based on discourse research in linguistics and ethnomethodology (Garfinkel, 1967). This method analyzes the communication process of two or more actors. In the present study, in view of the research purpose, we try to describe the interaction process at the group level from the standpoint of conversation analysis. In conversation analysis, it is necessary to approach the scene where a phenomenon is happening and to describe how members of society create the phenomenon in an organized way (Francis \& Hester, 2004). In conversation analysis, a conversation is not just an activity but a social action. Our utterances are shaped by collective order, and at the same time, the process forms with some intent regarding the behavior of others. In other words, conversation analysis can be regarded as a method that aims to describe the interaction relationship of social actions from the standpoint that the group order forms through interactions between individuals.

As a research area adjacent to business administration related to conversation analysis, research on "working" (workplace studies) has begun to accumulate, albeit little by little. Again, the formation of order through interaction is of primary concern. In a representative study, Suchman (1997) regarded air traffic control as a place for centers of coordination of various activities and described the complexity of information sharing and mutual understanding in decentralized situations inside and outside the control center. She argued that accumulating the order of daily interactions in such a specific workplace will be a source of future research and theorization. As a case study of an actual meeting place, Murphy (2005) depicted a way for architects to collaborate in imagining, focusing on three things: dialogue, gestures, and material objects. He stated that through such a method, it may be possible to shed light on the micro-level dynamics of social interactions. As described above, it is gradually becoming clear from the analysis of conversation data that it is possible to describe what kind of place is formed by interactions between members, even in the workplace.

\section{Outline and Purpose of this Research}

As mentioned in the previous section, a person's attitude is influenced by the behavior of others and changes while also affecting the attitudes of others through the act of expressing one's attitude to 
others. Especially in collective cooperative activities, the attitudes of group members are considered to engage in a dynamic process in which they influence and fluctuate relative to each other. However, it is not easy to clarify these relationships by questionnaire surveys and interviews. For methodological reasons, these relationships have not been deeply examined in the area of organizational behavior. Conversational analysis of collective collaborative situations using protocol data may make it possible to shed light on the complex and dynamic relationships of influence between group members.

Based on the above awareness of the problem, we try to describe the attitude change of group members by acquiring protocol data and analyzing conversation in the interaction process in a cooperative activity at the group level. Specifically, in this research, we explore the collaborative development of a new educational program through industry-academia collaboration and acquire conversation data at meetings. These data are categorized based on the utterance classification code (descriptive form code); the overall tendency is confirmed, and the descriptive pattern of the speaker in dialogue at the group level is identified. Based on that information, we describe how group member attitudes changed during the discussion. This study aims to examine the process of interaction and attitude vary among individuals in a group.

\section{Method}

\section{Data to be Analyzed}

In this paper, we analyze a case in which a higher education institution and multiple organizations in industry collaborated to develop a new educational program. The case study design involves a program with a new concept aimed at capturing history, culture, and industry from an integrated perspective in collaboration with multiple companies in the field in the region.

The reasons for selecting this case are described below. According to Fram and Clarcq (1978), in developing programs for industry and higher education, it is necessary to solicit opinions from industry and constantly scrutinize the value and content of those opinions. Although students are products from the perspective of society, they have the characteristic of being customers in higher education services. In other words, the perception of students differs between industry and members of higher education institutions. Therefore, in a collaborative educational program development meeting, the attitudes of participating members toward students may change under the influence of other group members. From the above, it was considered appropriate to describe the attitude changes of group members, which is the purpose of this study.

In this study, the contents of conversations at regular meetings for the collaborative design of this lesson subject were captured on an IC recorder with the consent of the participants and transcribed. Table 1 shows the general contents of each meeting. A maximum of six people (hereinafter referred to as A to F) participated in the meeting. A and B were associate professors of higher education institutions, and $\mathrm{C}$ to $\mathrm{F}$ were employees or sole proprietors of different companies. There was no formal job hierarchy for any of the members. Some participants were known to each other, but the first meeting was the first time that all six had a conversation together. Of the voice data acquired in this study, the third meeting, which only three people participated, was excluded from the analysis. The audio data for the 1 st and 2 nd meetings and the 4 th to 6 th meetings in which all six people participated were used as targets of analysis. The recording time for each session was approximately 90 to 120 minutes. 
Table 1

Outline of the Meeting

\begin{tabular}{lcll}
\hline \multicolumn{1}{c}{ Date } & \multicolumn{1}{c}{ Overview } \\
\hline 1 & 2017.9 .20 & Free discussion on the concept & \\
2 & 2017.11 .16 & Discussion on specific design & \\
3 & 2017.12 .26 & Follow-up by 3 main members & \\
4 & 2018.1 .25 & Re-sharing goals and finalizing lecture design & $\bigcirc$ \\
5 & 2018.3 .27 & Final meeting and detailed confirmation before the lecture & $\bigcirc$ \\
6 & 2018.8 .23 & Review of the entire lecture & $\bigcirc$ \\
\hline
\end{tabular}

\section{Analysis Method}

In this study, we first used a coding method to provide basic information for analyzing the protocol data. The coding method is a useful paradigm in conversational research, and it is possible to quantify utterances by classifying them into predetermined codes. The most basic coding method is to classify utterances from a descriptive form, such as the verbal response model of Stiles (1992). This method assesses the descriptive functions of utterances with codes such as "disclosure" and "question." For example, in a Japanese conversation study, Fujimoto and Daibo (2007a) conducted an experimental conversation session using university students as a sample and classified utterances using descriptive codes. Using those data, they showed that there are various types of speaker's descriptive patterns in small-group communication. Specifically, the central speaker proactively provides information and responds to questions from others. The elaborator plays an important role in encouraging conversation together as a recipient of the main speaker. The coordinator does not provide much information by himself or herself but emphasizes interactions such as encouraging others to speak. In addition, Fujimoto and Daibo (2007b) proposed a conversation development code that focuses on the development (depth) of conversation. In this way, utterances have various properties, so the knowledge that can be obtained differs depending on which aspect is the focus.

The purpose of this study is to describe the attitude changes of group members. Therefore, it is necessary to consider what kind of information and themes were presented in the conversation and what kinds of comments were received from other members. Therefore, we decided to code the utterance using the descriptive format code. In this study, a descriptive code is used to classify Japanese conversations. The coding was performed with reference to the method of Fujimoto and Daibo (2007a), which is an improvement on the verbal response model of Stiles (1992). Each speech turn of the participants was identified, and utterances were categorized based on the categories of information, comment, instruction, question, response, and reflection.

Table 2 shows the contents of each category of descriptive codes used in this study. Each category was created based on each descriptive format used in Fujimoto and Daibo (2007a). Of the six types of descriptive forms, information is a voluntary descriptive utterance that includes selfdisclosure. Similarly, the descriptive utterance comment is an utterance that includes voluntary views and impressions of the preceding statement.

The comment category was single-dimensional in Fujimoto and Daibo (2007a), but it was subdivided into three types and revised in this study. Specifically, the category of comments was further classified into three types, positive, flat, and negative, according to the purpose of the study. A positive utterance affirms the previous opinions of others or repeats the same opinions. A flat statement neither affirms nor denies the preceding opinion of another person, and a negative comment includes content that denies the preceding opinion of another person. In this way, we aimed to clarify the attitudes of each member and the process of their transformation by clarifying 
whether the utterances of the group members with respect to the attitudes expressed by preceding others are positive.

Instructions are utterances that ask a specific person to speak, including requests and orders, and support the content and flow of conversation. Questions are confirmations, such as asking questions to a particular person or the entire group and requests for consent. A response is an utterance involving an answer to a question or instruction posed to oneself, and reflection represents a phrase with no special meaning, such as an aizuchi or a short reply.

Table 2

Narration Format Code (Partially Modified from Fujimoto and Daibo (2007a)

\begin{tabular}{|c|c|c|}
\hline Code & Contents & Example \\
\hline Information & New information and opinions & "I think X is Y." "I like this idea." \\
\hline Comment & Opinions and impressions of other people's remarks & - \\
\hline (positive) & $\begin{array}{l}\text { Comments that affirm or agree with the statements of others } \\
\text { who precede }\end{array}$ & "I think it's interesting." "It's important." \\
\hline (flat) & $\begin{array}{l}\text { Comments that do not affirm or deny the statements of others } \\
\text { who precede }\end{array}$ & "I can't say anything." "You think so." \\
\hline (negative) & Comments denying the preceding others' remarks & "I don't think so" "I think it's difficult" \\
\hline Instruction & $\begin{array}{l}\text { Remarks that ask for remarks or instruct the content and flow } \\
\text { of conversation }\end{array}$ & "Do you have any opinions?" "What do you think?" \\
\hline Question & Confirmation of questions and consent requests & "What does that mean?" "Is XX okay?" \\
\hline Response & Answers to questions asked & "Yes, it's okay." "No, I think it's X." \\
\hline Reflection & A short phrase for an aizuchi or a call & "Yes." "uh-huh." "I see." \\
\hline
\end{tabular}

Based on Fujimoto and Daibo (2007a), this study also used a procedure to grasp the structure of one speech turn appropriately. The period from the start of an utterance by one speaker to the end of an utterance (until another speaker starts an utterance) is counted as one turn. Therefore, one utterance may contain multiple sentences. In a long turn, an utterance may be classified into multiple codes depending on the utterances included. An utterance in such a case was classified into multiple codes and counted. However, when consecutive utterances are classified with the same code, they are handled without being counted twice.

\section{Aim of Analysis}

In this study, we analyze conversation data with the following two aims. The first aim is to quantitatively confirm the basic tendency of the speaker type and the descriptive pattern in the work scene classified with a classified descriptive form code. Specifically, by confirming the expression ratio of the descriptive form category among the group members, we analyze the utterance structure of each speaker in the work scene meeting. This analysis aims to uncover the tendency of the speaker in the whole meeting.

On the other hand, conversations in work situations are often continuous rather than a single shot. Therefore, it is necessary to capture the changes in the narrative patterns of each speaker during the continuous meeting as basic information. Therefore, for each type of speaker, the consistency of the utterance pattern is analyzed by correlatively analyzing how similar the 
utterances of each speaker are between meetings. From the above, the utterance structure of this case is exploratory and clarified as basic information for analyzing conversations related to attitude change.

The second aim is to describe the attitude changes of group members via interpretive analysis of group-level utterance cases using descriptive codes. We clarify how group members' attitudes toward a particular subject have changed in real-time situations at meetings using descriptive categories and utterances. We thus seek to describe what kind of order emerged in the group and caused the attitude change among the group members, and we propose a hypothetical model that extends the ELM (Petty \& Cacioppo, 1986).

\section{Results}

\section{Structural Analysis of the Utterances of Group Members}

Classification of the overall tendency and descriptive patterns of utterances. Table 3 shows the results for all utterances for each speaker for each descriptive format category for the conversation data from the meeting. The average number of utterances in one meeting for all speakers was 88.83 . First, an analysis of variance was performed to examine whether the number of utterances differed among speakers, and a significant difference was found $(\mathrm{F}(5,24)=2.88, p$ $<.05)$. As a result of multiple comparisons by the Tukey method, a significant difference was found between Mr. A and Mr. F.

Table 3

Average Number of Utterances of Each Speaker and the Expression Ratio of Each Descriptive Format Code

\begin{tabular}{|c|c|c|c|c|c|c|c|c|c|c|c|c|c|c|c|}
\hline Speaker & $\begin{array}{c}\text { Average } \\
\text { number of } \\
\text { utterances }\end{array}$ & Information & & $\begin{array}{l}\text { Comment } \\
\text { (positive) }\end{array}$ & $\begin{array}{c}\text { Comment } \\
\text { (flat) }\end{array}$ & & $\begin{array}{l}\text { Comment } \\
\text { (negative) }\end{array}$ & Instruction & & Question & Response & Reflection & & & Judgment \\
\hline A & 149.20 & $\begin{array}{c}0.74 \\
(47.1 \%)\end{array}$ & & $\begin{array}{c}0.32 \\
(8.8 \%)\end{array}$ & $\begin{array}{c}0.2 \\
(3.8 \%)\end{array}$ & & $\begin{array}{c}0.14 \\
(1.7 \%)\end{array}$ & $\begin{array}{c}0.25 \\
(6.3 \%) \overline{\bar{\equiv}}\end{array}$ & & $\begin{array}{c}0.29 \\
(10.3 \%)\end{array}$ & $\begin{array}{c}0.42 \\
(16.9 \%)\end{array}$ & $\begin{array}{c}0.21 \\
(5.1 \%)\end{array}$ & & & Central speaker \\
\hline B & 84.60 & $\begin{array}{c}0.58 \\
(30.3 \%)\end{array}$ & & $\begin{array}{l}0.51 \\
(17.0 \%)\end{array}$ & $\begin{array}{l}0.15 \\
(5.0 \%)\end{array}$ & & $\begin{array}{l}0.08 \\
(1.2 \%)\end{array}$ & $\begin{array}{c}0.11 \\
(3.3 \%)\end{array}$ & & $\begin{array}{l}0.20 \\
(6.6 \%)\end{array}$ & $\begin{array}{c}0.38 \\
(13.2 \%)\end{array}$ & $\underset{(23.4 \%)}{0.44}=$ & ${ }^{*}$ & * & Elaborator \\
\hline $\mathrm{C}$ & 99.40 & $\begin{array}{c}0.49 \\
* \quad(22.9 \%)_{7}\end{array}$ & & $\begin{array}{c}0.45 \\
(19.5 \%)\end{array}$ & $\begin{array}{c}0.31 \\
(10.7 \%)\end{array}$ & & $\begin{array}{l}0.22 \\
(4.2 \%)\end{array}$ & $\underset{(0.0 \%)}{0.00}=$ & & $\begin{array}{l}0.39 \\
(14.3 \%) \square\end{array}$ & $\begin{array}{l}0.32 \\
(9.3 \%)\end{array}$ & $\left.\right|_{* *} \begin{array}{c}0.43 \\
(19.1 \%)\end{array}$ & 7 & $*$ & $\begin{array}{c}\text { Commentator } \\
\text { (Reflective type) }\end{array}$ \\
\hline $\mathrm{D}$ & 83.80 & $\begin{array}{c}0.72 \\
(43.2 \%)\end{array}$ & $* *$ & $\begin{array}{c}0.39 \\
(16.2 \%)\end{array}$ & $\begin{array}{c}0.31 \\
(10.3 \%)\end{array}$ & & $\begin{array}{l}0.15 \\
(2.1 \%)\end{array}$ & $\begin{array}{c}0.02 \\
* \quad(0.2 \%)\end{array}$ & & $\begin{array}{c}0.21 \\
(5.0 \%)\end{array}$ & $\begin{array}{c}0.41 \\
(15.8 \%)^{7}\end{array}$ & $\begin{array}{l}0.27 \\
(7.2 \%)\end{array}$ & & & $\begin{array}{c}\text { Commentator } \\
\text { (Responsive type) }\end{array}$ \\
\hline E & 86.80 & $\begin{array}{c}0.81 \\
(52.5 \%)\end{array}$ & & $\begin{array}{c}0.34 \\
(12.4 \%)\end{array}$ & $\begin{array}{c}0.28 \\
(7.8 \%)\end{array}$ & & $\begin{array}{lc}* * & 0.10 \\
& (1.8 \%)\end{array}$ & $\begin{array}{c}0.02 \\
(0.2 \%)\end{array}$ & & $\begin{array}{l}0.41 \\
(16.1 \%)\end{array}$ & $\left.\right|_{* *}\left(\begin{array}{c}0.21 \%) \\
(4.1 \%\end{array}\right.$ & $\begin{array}{l}0.22 \\
(4.8 \%)\end{array}$ & & & $\begin{array}{c}\text { Information } \\
\text { provider }\end{array}$ \\
\hline $\mathrm{F}$ & $29.20]$ & $\begin{array}{c}0.52 \\
(34.9 \%)\end{array}$ & & $\begin{array}{l}0.21 \\
(3.4 \%)\end{array}$ & $\begin{array}{l}0.08 \\
(2.1 \%)\end{array}$ & 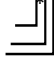 & $\begin{array}{l}0.03 \\
(0.7 \%)\end{array}$ & $\begin{array}{l}0.00 \\
(0.0 \%)\end{array}$ & & $\begin{array}{c}0.70 \sqsupseteq] \\
(40.4 \%)\end{array}$ & $\begin{array}{c}0.35 \\
(12.3 \%)\end{array}$ & $\begin{array}{l}0.16 \\
(6.2 \%)\end{array}$ & $\mathrm{f}^{* *}$ & & Questioner \\
\hline
\end{tabular}

Note 1$)^{*}: p<0.05, * *: p<0.01$

Note 2) Since the descriptive format code is ratio data, analysis of variance was performed using the value obtained by angularly converting the expression ratio for each time.

For convenience, the percentage of each code displayed in all meetings of each speaker is shown in parentheses.

Next, to examine the differences in the utterance structure of each speaker, the ratio of the descriptive format category for each speaker was calculated for each meeting, and analysis of variance was performed. Since the expression ratio of each category is ratio data, the numerical value after angular conversion was used in the analysis. As a result of analysis of variance, significant differences were found in information $(\mathrm{F}(5,24)=3.38, p<.05)$ and comment (flat) ( $\mathrm{F}$ $(5,24)=4.92, p<.01)$, comment (negative) $(\mathrm{F}(5,24)=3.78, p<.05)$, instruction $(\mathrm{F}(5,24)=$ $16.44, p<.001)$, question $(\mathrm{F}(5,24))=13.86, p<.001)$, response $(\mathrm{F}(5,24)=4.08, p<.01)$, and reflection $(\mathrm{F}(5,24)=6.45, p<.01)$. There was a significant difference in all categories except for comment (positive). The results of multiple comparisons via the Turkey method are shown in Table 3. 
Then, with reference to Fujimoto and Daibo (2007a), we tried to identify the descriptive pattern of each speaker. As shown in Table 3, Mr. A had a large proportion of utterances, instructions, and responses. He had a descriptive pattern of responding to questions from others while controlling the entire meeting. Therefore, he was determined to be a central speaker. Mr. B had a large proportion of instructions and reflexes. While controlling the flow of discussion to a certain extent, he seemed to have played the role of the receiver of the central speaker and contributed to livening up the conversation. Therefore, he was identified as an elaborator. $\mathrm{Mr}$. $\mathrm{C}$ had a large proportion of comments (flat), comments (negative), and reflexes and exhibited a descriptive pattern in which he spoke and responded to the opinions of others. This descriptive pattern was not confirmed by Fujimoto and Daibo (2007a) and was newly judged as the role of commentator (reflective type). Mr. D had a large proportion of comments and responses and often responded to questions asked by others. Therefore, unlike the commentator (reflective type), which often reacts spontaneously to the flow of conversation, Mr. D was judged to be the commentator (responsive type), a descriptive pattern that is often requested by others. Mr. E mainly provides information, and since there are relatively few statements oriented toward others, he is called an information provider. Mr. F was judged to be a questioner because his descriptive pattern focused on asking questions in response to the statements of others.

Intrapersonal correlation between meetings. Although few studies have examined continuous changes in narrative patterns, a structural analysis of teacher and child utterances in Japanese was conducted in educational psychology (Kishi \& Nojima, 2006). Those authors examined the coherence of speaker behavior by performing a correlation analysis of utterance categories between classes. In the current study, we decided to refer to that research and examined whether each speaker's utterances changed due to differences in the content of the meeting and the descriptive pattern. Then, based on all the descriptive format categories ( 8 items) for each speaker, the correlation between each meeting for each speaker was calculated.

As shown in the results in Table 4, the correlation coefficients ranged from -.10 to .99. As an index showing the consistency of the narrative pattern of each speaker, the percentage of combinations with significant correlations was calculated from the combinations of five meetings. This result showed that even the descriptive patterns for the same speaker are not always consistent. The descriptive pattern of the central speaker, commentator (responsive type), and informant has very strong stability regardless of the content of the meeting. On the other hand, elaborator, commentator (reflective type), and the questioner had relatively low consistency in the descriptive pattern. It was suggested that this speaker flexibly changed his descriptive pattern according to the flow of each conversation.

Table 4

Intraindividual Correlations between Meetings

\begin{tabular}{llcc}
\hline \multicolumn{1}{c}{ Speaker } & Correlation coefficient range & Consistency of descriptive patterns* \\
\hline A & Central speaker & $.83 \sim .99$ & $100 \%$ \\
B & Elaborator & $.45 \sim .91$ & $60 \%$ \\
C & Commentator (Reflective type) & $-.10 \sim .70$ & $0 \%$ \\
D & Commentator (Response type) & $.74 \sim .93$ & $100 \%$ \\
E & Information provider & $.89 \sim .98$ & $100 \%$ \\
F & Questioner & $-.05 \sim .96$ & $40 \%$ \\
\hline
\end{tabular}

$*$ : Percentage of significant combinations of intra-individual / inter-meeting correlations 


\section{Changes in the Utterances and Opinions of Group Members}

Next, we describe how each speaker's attitude changed in the conversation. Table 5 presents the utterance content for each speaker and the change of opinion on a specific theme. This case was the first meeting, where we set goals as a new educational program through social collaboration. This describes part of a free discussion about how they feel about students and the younger generation in recent years.

Initially, Mr. D (commentator (responsive type)) made a statement that expressed an opinion within the group, and subsequent comments (positive) continued to affirm themes such as the rudeness and lethargy of the younger generation. Specifically, the group members (Mr. A, Mr. C, and Mr. E) expressed unfavorable attitudes. As a result, 4 out of 6 people gave negative opinions (No. 1-1 to No. 1-6).

Subsequently, when all the opinions were gathered, Mr. B (elaborator) agreed with the unfavorable attitude and showed his understanding. Meanwhile, he made a comment (negative) denying "the lethargy of young people" in that "I wonder if they have different kinds of values," and expressing a neutral position (No. 1-7). Mr. B continued to exhibit a new theme (information), "the need to understand the difference in values," and expressed a favorable position toward the younger generation (No. 1-8).

Next, Mr. D (commentator (responsive type)), who had expressed a negative attitude toward the younger generation initially, made an utterance (comment (flat)) showing his understanding of Mr. B's raising of the problem (No. 1-9). Therefore, it was judged that Mr. B expressed a neutral attitude. Subsequently, although some utterances showed unfavorable attitudes toward the younger generation, Mr. C, Mr. E, and Mr. F gradually showed a neutral attitude toward the younger generation (No. 1-10 to No. 1-12). Furthermore, in No. 1-19, Mr. D (commentator (responsive type)) showed a favorable attitude toward affirming the possibilities for the younger generation, saying that "maybe the contents are burning." Mr. A, who was the main speaker, showed an unfavorable attitude until the end (No. 1-20). However, he also finally expressed a neutral attitude, proposing a roundtable discussion between students and adults to discuss their true intentions, and settled the discussion (No. 1-21). 
Table 5

Discussions on the Younger Generation and Examples of Changes in the Attitudes of Group Members (1st Session)

\begin{tabular}{|c|c|c|c|c|c|c|c|c|}
\hline \multirow[b]{2}{*}{ No } & \multicolumn{3}{|c|}{ Utterance content and its classification } & \multicolumn{5}{|c|}{ Opinion (attitude) toward the younger generation } \\
\hline & Speaker & Utterance content & Topic & $\begin{array}{c}\text { Narration } \\
\text { format code }\end{array}$ & Negatively & Neutral & Favorable & Unknown \\
\hline $1-1$ & $\mathrm{D}$ & $\begin{array}{l}\text { By doing this this time, I also wish I could teach or convey one wording and etiquette part in it. I wonder if } \\
\text { young people are very scarce these days. }\end{array}$ & Youth rudeness & Information & D & & & $\mathrm{A}, \mathrm{B}, \mathrm{C}, \mathrm{E}, \mathrm{F}$ \\
\hline $1-2$ & $\mathrm{~A}$ & Actually, I think it's only during job hunting. & & $\begin{array}{l}\text { Comment } \\
\text { (positive) }\end{array}$ & $\overleftarrow{A, D}$ & & & $\mathrm{~B}, \mathrm{C}, \mathrm{E}, \mathrm{F}$ \\
\hline $1-3$ & A & How about that from the perspective of a hiring interview? & & Question & & & & \\
\hline $1-4$ & $\mathrm{C}$ & $\begin{array}{l}\text { Perhaps, as Mr. A said, they are doing well during such activities. Instead, they stop greeting when they think } \\
\text { the company is loose. It's a bad word for my company, but there are a lot of young people who don't return } \\
\text { even if I say hello. }\end{array}$ & & Response & $\mathrm{A}, \stackrel{\leftarrow}{\mathrm{C}, \mathrm{D}}$ & & & $\mathrm{B}, \mathrm{E}, \mathrm{F}$ \\
\hline $1-5$ & $\mathrm{D}$ & $\begin{array}{l}\text { We have to fix the fundamental part of human relationships. Our company was like that at the beginning, but } \\
\text { gradually I started to say hello. However, I think it's not easy to start from the bottom without the upper } \\
\text { management. }\end{array}$ & & $\begin{array}{l}\text { Comment } \\
\text { (positive) }\end{array}$ & & & & \\
\hline & & (Abbreviation) & & & & & & \\
\hline $1-6$ & $\mathrm{E}$ & $\begin{array}{l}\text { They don't want to say that at all. They don't have the desire to do that, to do this, to be like this. } \\
\text { (Abbreviation) }\end{array}$ & Youth lethargy & Information & $\mathrm{A}, \mathrm{C}, \mathrm{D}$ & & & F \\
\hline $1-7$ & B & $\begin{array}{l}\text { I thought for a moment. I think you're right, but from a relatively younger standpoint, I think it's true that they } \\
\text { don't have greed, and I think it's better to have greed. But I think they feel they don't really need it. What } \\
\text { should I say? In a way, if I have the shoulders of young people, I wonder if they have values in different } \\
\text { places. }\end{array}$ & & $\begin{array}{l}\text { Comment } \\
\text { (negative) }\end{array}$ & $\mathrm{A}, \mathrm{C}, \mathrm{D}, \mathrm{E}$ & & & $\mathrm{F}$ \\
\hline $1-8$ & B & $\begin{array}{l}\text { For example, not "I want a car". For example, on the contrary, they have a desire to connect with people and } \\
\text { live happily every day. I think it's better to connect from a different switch there. On the contrary, some } \\
\text { people are now connected with SNS, for example, to carry out various activities. I think there are pros and } \\
\text { cons to that. However, because their values have changed, they are really looking for something like a } \\
\text { connection or bond with a different person. I feel that they do not want money or things, but also want to } \\
\text { contribute to society. }\end{array}$ & $\begin{array}{l}\text { The need to } \\
\text { understand the } \\
\text { difference in } \\
\text { values }\end{array}$ & Information & $\mathrm{A}, \mathrm{C}, \mathrm{D}, \mathrm{E}$ & & B & $\mathrm{F}$ \\
\hline $1-9$ & $\mathrm{D}$ & $\begin{array}{l}\text { I'm sure the other person's values are different. If we really do this, we may gradually get closer together with } \\
\text { the students and understand each other better. At that time, we may also understand where the greedy people } \\
\text { are heading. On the contrary, they may be able to deepen their understanding of the muddy things that the old } \\
\text { men are doing. (abridgement) }\end{array}$ & & Comment (flat) & $\mathrm{A}, \mathrm{C}, \mathrm{E}$ & D & B & $\mathrm{F}$ \\
\hline & & (Abbreviation) & & & & & & \\
\hline $1-10$ & $\mathrm{C}$ & $\begin{array}{l}\text { However, I think that there must be more opportunities for mutual understanding in that } \\
\text { part.(Abbreviation)The difference is natural, so rub it well there.(Abbreviation) }\end{array}$ & & Comment (flat) & $\mathrm{A}, \mathrm{E}$ & $\stackrel{b}{\mathrm{C}, \mathrm{D}}$ & B & $\mathrm{F}$ \\
\hline & & (Abbreviation) & & & & & & \\
\hline $1-11$ & E & $\begin{array}{l}\text { I, but I don't think it's necessary to let a child who doesn't like communication communicate with me. If you } \\
\text { look at this Japan and look at this town, I think they have their role and whereabouts. (Abbreviation) I think } \\
\text { everyone has their own mission in their role. I actually want them to be aware of it. } \\
\text { (Abbreviation) }\end{array}$ & $\begin{array}{l}\text { Young people } \\
\text { are unaware of } \\
\text { what they lack }\end{array}$ & $\begin{array}{l}\text { Comment } \\
\text { (negative) }\end{array}$ & A & C,D,E & B & \\
\hline $1-12$ & $\mathrm{~F}$ & $\begin{array}{l}\text { Rather, while listening to the story, there was a plan to call them and exchange opinions on greed. The staff } \\
\text { may ask them. "What do you think of those nuances? " Some children speak fairly casually, while others are } \\
\text { not good at speaking a little. That's why, in a sense, there are students like this, or maybe it's good to connect } \\
\text { their desires to these things. (Abbreviation) }\end{array}$ & $\begin{array}{l}\text { Need to } \\
\text { promote mutual } \\
\text { understanding in } \\
\text { the forum for } \\
\text { exchanging } \\
\text { opinions }\end{array}$ & Information & A & C,D,E, & B & \\
\hline $1-13$ & B & $\begin{array}{l}\text { Surely. Then, the first and second graders have a soft head, they are close to their age, and their true } \\
\text { intentions are easy to say. }\end{array}$ & & $\begin{array}{l}\text { Comment } \\
\text { (positive) }\end{array}$ & & & & \\
\hline & & (Abbreviation) & & & & & & \\
\hline $1-14$ & B & $\begin{array}{l}\text { Perhaps it's my own idea, but the young people I've been involved with are taking it seriously and are actually } \\
\text { quite motivated. However } \cdots \text {, }\end{array}$ & $\begin{array}{l}\text { Opinions that } \\
\text { affirm young } \\
\text { people }\end{array}$ & Information & & & & \\
\hline $1-15$ & $\mathrm{D}$ & How to show it. & & Information & & & & \\
\hline $1-16$ & B & They don't know how to do it. & & Information & & & & \\
\hline $1-17$ & A & It's the same as if we can't see it. & & $\begin{array}{l}\text { Comment } \\
\text { (negative) }\end{array}$ & & & & \\
\hline $1-18$ & B & It's surprisingly pure and sensitive. & & Information & & & & \\
\hline $1-19$ & $\mathrm{D}$ & Maybe the contents are burning. They may not know how to put it out, and certainly. & & $\begin{array}{l}\text { Comment } \\
\text { (positive) }\end{array}$ & A & C,E,F & $\mathrm{B}, \mathrm{D}$ & \\
\hline $1-20$ & A & In the words of Mr. D, it's soft, isn't it? & & $\begin{array}{l}\text { Comment } \\
\text { (positive) }\end{array}$ & & & & \\
\hline & & (Abbreviation) & & & & & & \\
\hline $1-21$ & A & $\begin{array}{l}\text { So I thought while listening to the story. There was a story that it might be interesting to talk with students in } \\
\text { areas where there may be temperature differences. So, after a hot adult talks about it, we have a roundtable } \\
\text { discussion with the students during class time. (Omitted) About half a day with a lecture and a roundtable } \\
\text { discussion. Next day's fieldwork. When they come back, I think it's a good idea to be able to summarize some } \\
\text { post-event activities or take some action to connect to the next. }\end{array}$ & & Information & & $\grave{A}, C, E, F^{\prime}$ & B,D & \\
\hline
\end{tabular}


At the 2nd to 5th meetings, a meeting was held to discuss the details of the educational program design. As a result, a proposal for a plan that emphasizes collaboration and practicability was created through roundtable discussions between students and working people and fieldwork in regions and industries in the new lesson subjects. The sixth meeting was held to reflect on those achievements and issues. The related contents are shown in Table 6. Mr. A, Mr. E, and Mr. F, who showed a neutral attitude in the first session, expressed their opinions, which were triggered by the remarks of Mr. A and Mr. D (No. 2-2 to No. 2-3). Their utterances indicate that their attitudes changed from neutral to favorable through their actual behavior (No. 2-4 to No. 2-7). Mr. C expressed no specific opinion regarding the younger generation.

Table 6

Discussions on the Younger Generation and Examples of Changes in the Attitudes of Group Members (6th)

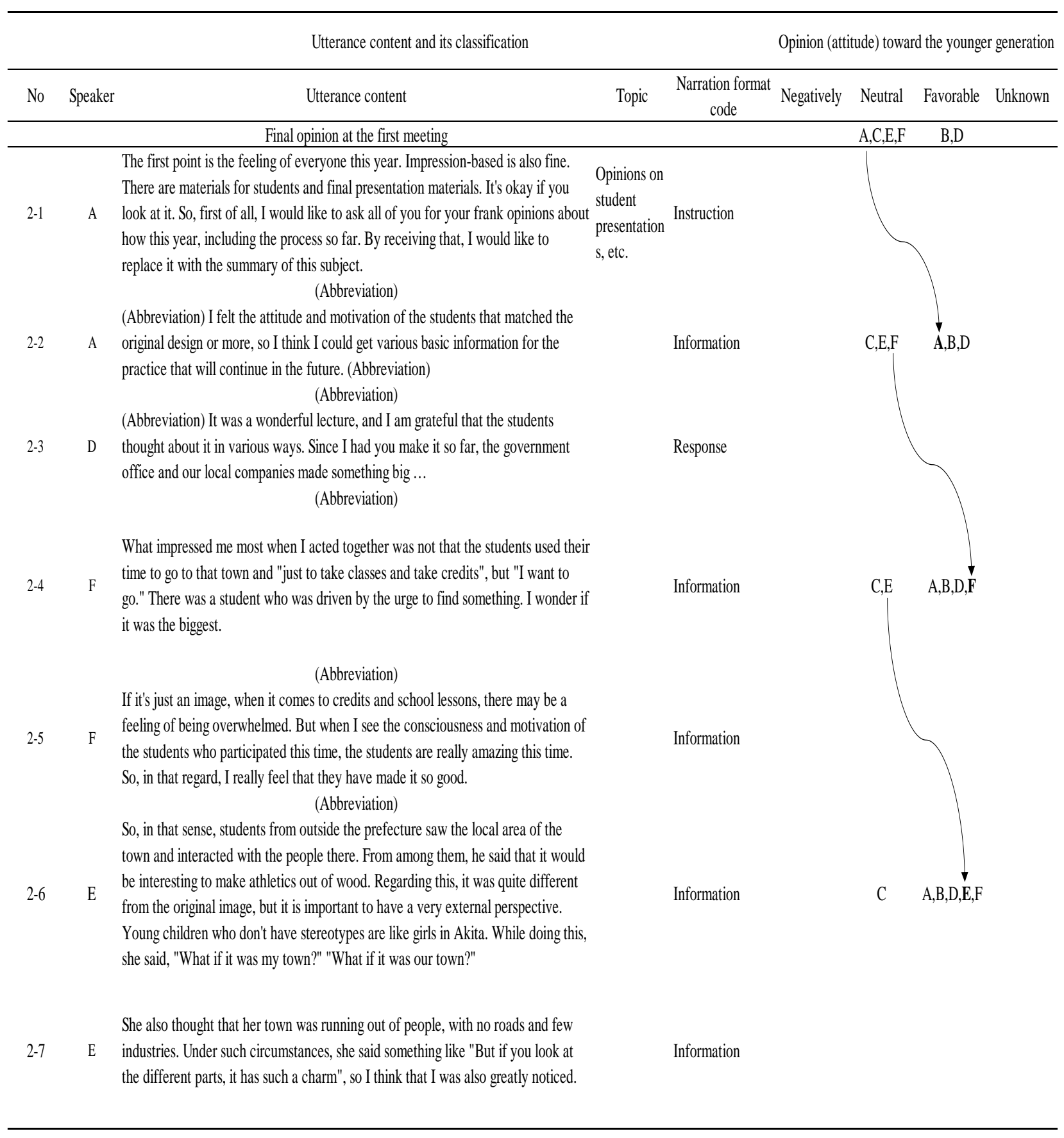




\section{Discussion}

\section{Classification and Consistency of Descriptive Patterns}

In this study, we classified each speaker's narrative pattern into six types of interaction scenes in a group-level dialogue at work. In Fujimoto and Daibo (2007a), data were acquired for university students, but the present study confirmed some characteristics thought to result from targeting group-level interaction scenes at work.

First, Mr. A and Mr. B played the complementary roles of central speaker and elaborator. The interview confirmed that they did not make any prior arrangements regarding meeting roles and how to proceed with the discussion. Both of them belonged to the same organization as teachers and were in a position to plan mainly educational programs, so complementary conversational behaviors emerged unconsciously. Previous studies have shown that speakers with complementary roles have better conversational performance (Fujimoto \& Daibo, 2007a; Fujimoto, Murayama, \& Daibo, 2004). In the case study, each speaker controls the setting of the discussion while uttering complementary roles. According to Rico, Sánchez-Manzanares, Gil, and Gibson (2008), there is implicit and proper coordination between members without explicit communication through language within the team. In this study, an implicit cooperative relationship may have occurred in terms of the speaker's role and the pattern of speech. This point is one of the quantitatively analysis results using descriptive form codes as the basic data for conversation analysis.

Second, the analysis of intraindividual correlation showed that the consistency of speech behavior differs depending on the descriptive pattern of the individual. Regarding the consistency of such utterance patterns, the interclass correlation of teachers in educational psychology has been examined, and very strong consistency has been confirmed (Kishi \& Nojima, 2006). However, the consistency of the descriptive pattern may differ depending on the speaker's role in the interaction scene at the work group level, likely because this case was not "one-to-many" but "many-to-many" communication and the relationship of the members between the organizations was relatively flat. Naturally, the central speaker, commentator (responsive type), and information provider adopted the style of consistently transmitting information. On the other hand, the members who served as elaborators, commentators (reflective type), and questioners spoke while flexibly changing their styles as recipients of the information. Such a place relationship (order) may have formed in a continuous meeting. The consistency of this descriptive pattern may be revealed only by analyzing data from continuous speech. In the future, examining the relationship with variables such as the individual speaker characteristics and group characteristics may aid in elucidating the longitudinal ordering mechanism.

\section{Attitude Changes among Members of the Group}

In this study, based on the abovementioned classification via descriptive codes, we aimed to describe the attitude changes among group members in the interaction scene at the group level. Mr. B, an elaborator, had a flexible and sympathetic attitude but consistently had a positive attitude toward the younger generation. In addition, his utterances inspired a neutral attitude among the others. He may have exercised minority influence by keeping pace with the opinions of the majority, but with a constant and consistent response to a particular opinion (Nemeth et al., 1974). The impact of minorities is significant, especially when they are in line with trends in the external environment of the group and have positive significance for the group in the future (Paicheler, 1977). Such utterances are believed to have promoted changes in the attitudes of other members. 
Mr. A, who is the main speaker, proposed to incorporate a roundtable discussion into the lecture to exchange discussion of values among working people and students while he maintained negative opinions about the younger generation until the end. This point may have led to the acceptance of small demands by other members who came to adopt a neutral attitude (sneak-in technique), as well as the favorable attitude of the group members as a result of prioritizing action (Festinger, 1957).

As discussed in the previous section, post-interview results indicate that Mr. A and Mr. B dared to express conflicting attitudes and changed the overall opinion while respecting the opinions of members of other organizations. There are few practical discussions of such implicit coordination in existing research, and it is necessary to discuss with a view of industrial and organizational situations. In this study, we addressed this point by describing practical situations at work. In particular, in the relatively flat cooperative activities between organizations discussed in this case, it is difficult to influence the other party through the official power of superiors and subordinates, unlike within an organization. Therefore, in this case, an order emerged in which the opinions of outside parties of higher education institutions were respected, and mutual attitudes formed gradually while facing others' opinions.

Furthermore, the attitudes of Mr. C, Mr. E, and Mr. F changed in accordance with the remarks of Mr. D, who was a commentator (responsive type). According to Fujimoto and Daibo (2007a), the more popular the speaker, the more often other members will talk to him or her. Mr. D had a high rate of expression in the response category and received many questions from others. Hence, Mr. D was very popular as a speaker within the group. Therefore, Mr. D's utterance may have triggered a change in the attitudes of others.

Based on the above considerations, Figure 1 presents a hypothetical model of the attitude changes among group members in this study. This hypothetical model can be regarded as an extension of the ELM. On that basis, the following two theoretical extensions are suggested. First, in the process of expressing attitudes in meetings between multiple organizations, it may be effective to promote attitude change while considering the attitudes of members of other organizations through minority influence and implicit coordination. In this case, each member changes their attitude from unfavorable to neutral through such discussions during the conversation. However, as the ELM points out, if individual knowledge and judgments are insufficient for a certain matter, fundamental information processing does not occur. As a second theoretical extension, empirical information in the conversation at the meeting and outside the meeting may function effectively as a central route for information processing. Regarding the above points, it is necessary to verify the hypothesis in future research. 


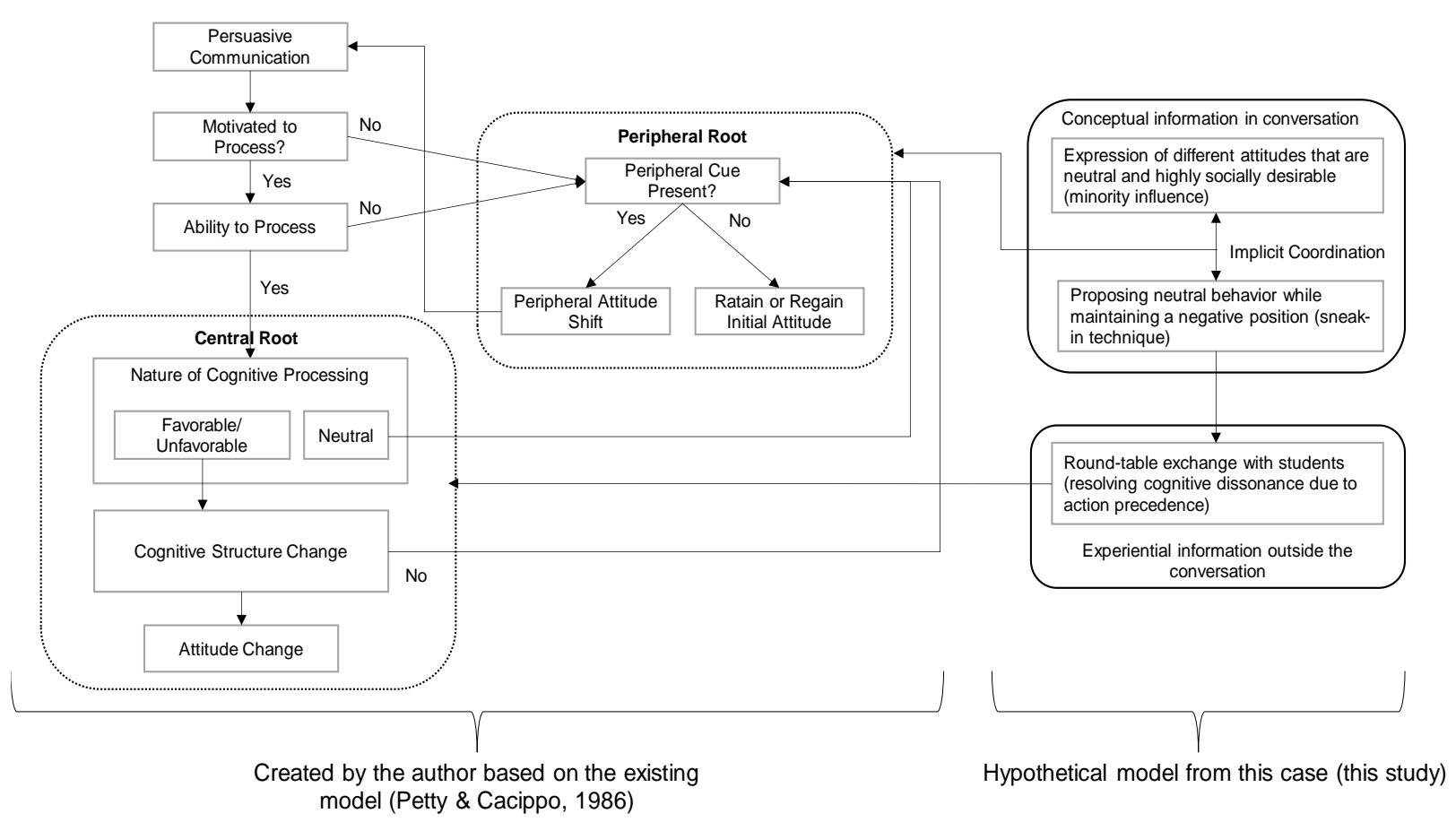

Figure 1. Hypothetical model for attitude changes among group members derived from this case.

\section{Significance of this Research and Future Research Issues}

In this study, we were able to describe the complex characteristics of group-level attitude changes that cannot be captured by methods such as questionnaire surveys and interviews. As mentioned at the beginning, the attitudes of group members have an informational function and an interpersonal function, and there is a dynamic and complicated process in which the attitudes influence each other. However, because of methodological problems, this point has not been fully examined in the area of organizational behavior. In this study, we adopted a conversation analysis method using protocol data and described the collaborative activities of group members in a work setting. We were thus able to analyze the sequence of interactions within a group as an example.

In particular, in collective situations such as team activities and projects, both individual behavior and the behavior of the entire group must be captured in an integrated manner, and it is thus necessary to visualize an actual organizational setting. Against this backdrop, this study focused on conversations in meeting situations. In the area of organizational behavior, it may be necessary to reexamine the situation of an organization as much as possible, including participant observation and ethnography. However, such a method cannot verify the causal relationship of the phenomenon. Therefore, it is necessary to adopt an approach based on questionnaire surveys and research using interviews.

Next, I would like to touch on the practical significance of this research. In this study, different attitudes were expressed among the organizations, and the development of an education program for industry-academia collaboration was considered an example of group influence. In addition to such cases, the research findings are considered applicable to changes in members' attitudes in situations such as new business projects and new product development. The findings could also be applied to attempts to deliberately control members' attitudes within an organization, such as the process of gaining employee acceptance when introducing new human resource management measures. 
The following two points can be considered as future research topics. The first is to analyze utterance data from a wider variety of perspectives. For example, themes related to the formation of power relationships in discussions, including the popularity of speakers, can be important, especially in industry and organizational contexts. In addition, for the coding of utterances, we used descriptive codes for basic analysis. However, by focusing on conversational development such as abstraction and materialization (Fujimoto \& Daibo, 2007b), future research may describe emergent situations that result in the creation of new concepts. The second point is to examine the change in attitudes at the group level from a more critical point of view. In this study, we analyzed the "expression" of attitudes in conversation as the attitudes of group members. Interestingly, the results were a kind of planned, harmonious order within a specific group. However, these results also indicate that there are social impacts and evaluation concerns within the population. Therefore, it was not possible to clarify in this study whether the attitudes of the group members truly changed. Therefore, future studies should retrospectively reexamine the true intentions and visible behaviors through interviews with participants.

\section{References}

Anzai, Y., \& Simon, H. A. (1979). The theory of learning by doing. Psychological Review, 86(2), 124. https://doi.org/10.1037/0033-295X.86.2.124.

Asch, S. E. (1951). Effects of group pressure on the modification and distortion of judgments. In H. Guetzkow (Ed.), Groups, leadership and men (pp. 177-190). Pittsburgh, PA: Carnegie Press.

Baron, R. S., \& Roper, G. (1976). Reaffirmation of social comparison views of choice shifts: Averaging and extremity effects in an autokinetic situation. Journal of Personality and Social Psychology, 33(5), 521-530. https://doi.org/10.1037/00223514.33.5.521.

Basadur, M., Graen, G. B., \& Scandura, T. A. (1986). Training effects on attitudes toward divergent thinking among manufacturing engineers. Journal of Applied Psychology, 71(4), 612-617. https://doi.org/10.1037/0021-9010.71.4.612.

Burger, J. M. (1999). The foot-in-the-door compliance procedure: A multiple-process analysis and review. Personality and Social Psychology Review, 3(4), 303-325. https://doi.org/10.1207/s15327957pspr0304_2.

Chaiken, S., Liberman, A., \& Eagly, A. H. (1989). Heuristic and systematic information processing within and beyond the persuasion context. In J. S. Uleman \& J. A. Bargh (Eds.), Unintended Thought (pp. 212-252). New York, NY: The Guilford Press.

Eagly, A. H., \& Chaiken, S. (1993). The psychology of attitudes. New York, NY: Harcourt Brace.

Eagly, A. H., \& Chaiken, S. (1998). Attitude structure and function. In D. T. Gilbert, S. T. Fiske, \& G. Lindzey (Eds.), The handbook of social psychology (4 ${ }^{\text {th }}$ ed., Vol. 1, pp. 269-322). New York, NY: McGraw-Hill.

Edmondson, A. C. (2002). The local and variegated nature of learning in organizations: A group-level perspective. Organization Science, 13(2), 128-146. https://doi.org/10.1287/orsc.13.2.128.530.

Ericsson, K. A., \& Crutcher, R. J. (1991). Introspection and verbal reports on cognitive processes-two approaches to the study of thinking: A response to Howe. New Ideas in Psychology, 9(1), 57-71. https://doi.org/10.1016/0732-118X(91)90041-J.

Ericsson, K. A., \& Simon, H. A. (1993). Protocol analysis: Verbal reports as data. MIT Press, Cambridge, MA.

Festinger, L. (1957). A theory of cognitive dissonance. Stanford, CA: Stanford University Press.

Fram, E. H., \& Clarcq, J. R. (1978). Commercial marketing techniques in continuing education. Lifelong Learning: The Adult Years, 2(1), 16-19.

Francis, D., \& Hester, S. (2004). An invitation to ethnomethodology: Language, society and interaction. Sage.

Freedman, J. L., \& Fraser, S. C. (1966). Compliance without pressure: the foot-in-the-door technique. Journal of Personality and Social Psychology, 4(2), 195. https://doi.org/10.1037/h0023552. 
Fujimoto, M., \& Daibo, I. (2007a). Participants' predication patterns in small group communications. Japanese Journal of Social Psychology, 23(1), 23-32.

Fujimoto, M., \& Daibo, I. (2007b). Conversation development patterns in small group interactions. Japanese Journal of Experimental Social Psychology, 47(1), 51-60. https://doi.org/10.2130/jjesp.47.51.

Fujimoto, M., Murayama, A., \& Daibo, I. (2004). What ensures a small-group discussion efficient? In The influence of group structure on various aspects of the small-group discussion. Paper presented at the 28th International Congress of Psychology.

Garfinkel, H. (1967). Studies in ethnomethodology. Englewood Cliffs, NJ: Prentice-Hall.

Janis, I. L. (1972). Victims of groupthink. Boston, MA: Houghton Mifflin Company.

Kishi, T., \& Nojima, E. (2006). A structural analysis of elementary school teachers' and children's utterances in Japanese classes. Japanese Journal of Educational Psychology, 54(3), 322-333. https://doi.org/10.5926/jjep1953.54.3_322.

Latané, B., Williams, K., \& Harkins, S. (1979). Many hands make light the work: The causes and consequences of social loafing. Journal of Personality and Social Psychology, 37(6), 822-832. https://doi.org/10.1037/0022-3514.37.6.822.

Lott, A. J., \& Lott, B. E. (1968). A learning theory approach to interpersonal attitudes. In A. G. Greenwald, T. C. Brock, \& T. M. Ostrom (Eds.), Psychological foundations of attitudes (pp. 67-88). New York, NY: Academic Press.

Murphy, K. M. (2005). Collaborative imagining: The interactive use of gestures, talk, and graphic representation in architectural practice. Semiotica, 2005(156), 113-145. https://doi.org/10.1515/semi.2005.2005.156.113.

Nemeth, C., Swedlund, M., \& Kanki, B. (1974). Patterning of the minority's responses and their influence on the majority. European Journal of Social Psychology, 4(1), 53-64. https://doi.org/10.1002/ejsp.2420040104.

Newell, A., \& Simon, H. A. (1972). Human problem solving (Vol. 104, No. 9). Englewood Cliffs, NJ: Prentice-hall.

Paicheler, G. (1977). Norms and attitude change II: The phenomenon of bipolarization. European Journal of Social Psychology, 7(1), 1-14. https://doi.org/10.1002/ejsp.2420070102.

Petty, R. E., \& Cacioppo, J. T. (1986). The elaboration likelihood model of persuasion. Advances in Experimental Social Psychology, 19, 123-205. https://doi.org/10.1016/s0065-2601(08)60214-2.

Rico, R., Sánchez-Manzanares, M., Gil, F., \& Gibson, C. (2008). Team implicit coordination processes: A team knowledge-based approach. Academy of Management Review, 33(1), 163-184. https://doi.org/10.5465/amr.2008.27751276.

Stiles, W. B. (1992). Describing talk: A taxonomy of verbal response modes. Newbury Park, CA: Sage Publications.

Suchman, L. (1997). Centers of coordination: A case and some themes. In L. B. Resnick, R. Saljo, C. Pontecorvo, \& B. Burge (Eds.), Discourse, tools, and reasoning: Essays on situated cognition (pp. 41-62). Berlin: Springer-Verlag.

Van Maanen, J., \& Schein, E. H. (1979). Toward a theory of organizational socialization. In B. M. Staw (Ed.), Research in organizational behavior (pp. 84-89). New York, NY: JAI Press.

West, M. A. (1996). Reflexivity and work group effectiveness: A conceptual integration. In M. A. West (Ed.), Handbook of work group psychology (pp. 555-579). Chichester: John Wiley. 